\title{
LakeVOC-A Computer Model to Estimate the Concentration of Volatile Organic Compounds in Lakes and Reservoirs
}

\author{
By David A. Bender, William E. Asher, and John S. Zogorski
}

\section{Introduction}

Lakes and reservoirs are important sources of drinking water and some are used extensively for recreational purposes. On the basis of information in the U.S. Environmental Protection Agency's Safe Drinking Water Information System database, approximately 124 million people in the United States (47 percent of the population served by public water supplies) are served by public water suppliers that use a lake or reservoir as one of their source waters. Furthermore, the drinking water of approximately 34 million people is derived exclusively from a lake or reservoir (Marilee A. Horn, U.S. Geological Survey, written commun., August 26, 2002). Recreational activities on lakes and reservoirs include swimming, fishing, water skiing, boating, sailing, racing, and wind surfing. Because so many lakes and reservoirs are used for both recreation and drinking-water sources, there is a need for simplified tools to estimate the levels of contaminants in these water bodies from recreational activities and to evaluate management options.

Volatile organic compounds (VOCs), especially gasoline-related compounds, have been found in lakes and reservoirs in the northeastern United States (Baehr and Zapecza, 1998; Baehr and Reilly, 2001), Lake Tahoe, in Nevada and California (Boughton and Lico, 1998; Lico and Pennington, 1999), California (Reuter and others, 1998; Dale and others, 2000), and Texas (Mahler, 2000). Recreational boating on lakes and reservoirs using marine engines, especially older twocycle engines, introduces gasoline-related organic compounds through emission of non-combusted fuel, including methyl tert-butyl ether (MTBE), benzene, toluene, ethylbenzene, and xylenes to water bodies (Jüttner, 1988, 1994; van Donkelaar, 1988; Jüttner and others, 1995a, 1995b; Dale and others, 2000; Gabele and Pyle, 2000). Other possible sources of gasoline-related VOCs to lakes and reservoirs include accidental spills from fueling operations, leaking underground fuel storage tanks or pipelines, overland stormwater runoff, and streamflow and atmospheric inputs.

The U.S. Geological Survey, in cooperation with the University of Washington and Oregon Health \& Science University, developed a publicly available computer model to estimate the concentration of a user-selected VOC in a lake or reservoir. The model, called LakeVOC, is specifically intended as a planning tool and can be used by water utilities and govern-

\begin{abstract}
ment agencies to estimate a time series of concentrations of gasoline-related VOCs expected from various intensities and mixes of recreational watercraft. Other sources of gasoline-related VOCs to lakes and reservoirs also can be investigated using LakeVOC including, for example, accidental spills from fueling operations, leaking gasoline pipelines, leaking gasoline storage tanks, stormwater runoff, and atmospheric inputs. Advantages of LakeVOC are its ease of use and the ability to quickly evaluate a large number of strategies to reduce gasoline-related compounds in reservoirs and lakes.
\end{abstract}

\section{Model Description and Input Parameters}

LakeVOC represents a lake or reservoir as a two-layer system and

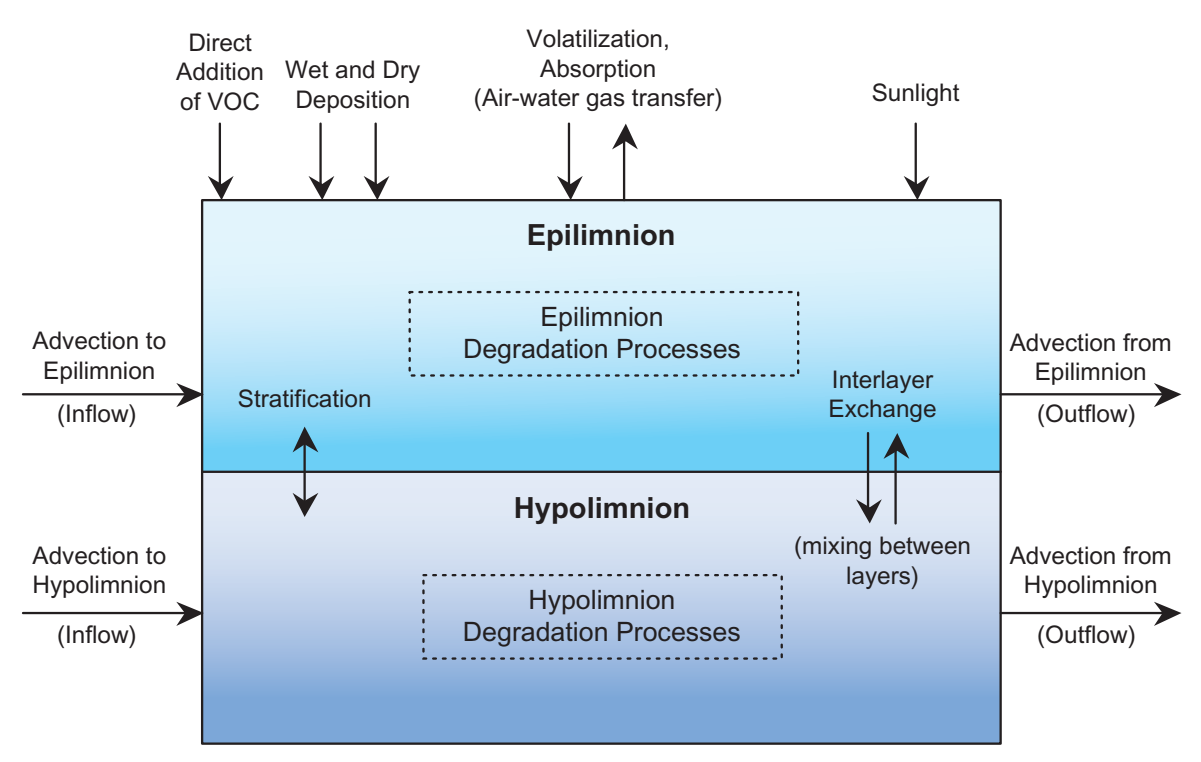

Figure 1. Schematic diagram showing the transport, behavior, and fate processes modeled by LakeVOC for volatile organic compounds in lakes and reservoirs. 
estimates the concentration of an individual user-selected VOC in both the epilimnion (uppermost mixed layer of water in a lake) and hypolimnion (lowermost mixed layer of water in a lake). The model integrates the coupled system of differential equations for the concentration of the VOC in the epilimnion and hypolimnion, the total mass of the VOC in the lake, and the volume of the epilimnion and the hypolimnion. LakeVOC accounts for changes in concentration caused by mixing between the two layers, direct addition of a VOC to the lake, loss of a VOC through lake outflows, air-water gas transfer of a VOC from the lake surface, and degradation processes. These processes are depicted schematically in figure 1 .

The hydrodynamics of lake mixing and stratification are characterized in the model through user-entered time series for the depth of the epilimnion, lake depth, and lake inflows and outflows. The total lake volume is determined from the lake-depth time series and a separate user-entered relation of lake-surface area to lake depth. Water is added to the lake by inflow and (or) precipitation through a user-specified inflow rate. Water is removed from the lake by outflow and evaporation through a userspecified outflow rate. The depths of the user-specified inflows and outflows are independent and may be placed in either the epilimnion or hypolimnion through user-specified inflow and outflow depths.

The gas transfer caused by air-water flux of a VOC is characterized in LakeVOC in terms of the two-film model of air-water exchange (Lewis and Whitman, 1924; Schwarzenbach and others, 1993; Rathbun, 2000). Although the two-film model oversimplifies the hydrodynamics associated with gas-liquid transfer, it provides a useful framework for estimating the rate of air-water exchange of VOCs. Air-water gas transfer is characterized in terms of the air-water concentration difference and the wind speed using the relation of Wanninkhof and others (1991). Evaporation is characterized using the wind speed relation of Schwarzenbach and others (1993) assuming a relative humidity of 70 percent.

LakeVOC estimates the daily concentration of a user-selected VOC in a lake or reservoir for a year or several years. Meteorological, hydrographical, VOC mass-input, and VOC physical-chemical properties are required to execute the model. Input parameters for the Lake-
VOC model are listed in table 1. Daily, weekly, or monthly time-series input parameters can be used; however, daily time-series values provide the best fit of the model results with measured VOC water concentrations.

The model hydrographical and meteorological inputs are available from monitoring programs and weather stations. The atmospheric VOC concentrations may be obtained from state or local airquality monitoring program sites located near the lake or reservoir. Recreational watercraft VOC inputs can be estimated on the basis of boat usage information from the recreational management agency for the lake or reservoir and mass emission rates reported in the literature.

\section{Model Verification}

Details of the verification of the LakeVOC model are given in Bender and others (2003). A short summary of simulations using a hypothetical lake and an actual reservoir from Bender and others (2003) are provided in this section.

\section{Simulations Using a Hypothetical Lake}

The LakeVOC model was verified, in part, by using a series of controlled simu-

Table 1. LakeVOC model input parameters.

$\left[{ }^{\circ} \mathrm{C}\right.$, degrees Celsius; $\mathrm{m}^{2}$, square meters; $\mathrm{m}^{3}$, cubic meters; VOC, volatile organic compound; ppbv, parts per billion by volume; $\mu \mathrm{g} / \mathrm{L}$, micrograms per liter; $\mathrm{Pa}-\mathrm{m}^{3} / \mathrm{mole}$, Pascals-cubic meters per mole]

\begin{tabular}{|c|c|c|c|}
\hline Type of parameter & Parameter & Units & $\begin{array}{c}\text { Time scale of input } \\
\text { parameters }\end{array}$ \\
\hline \multirow[t]{4}{*}{ Meteorological } & Wind speed & meters per second & Daily, weekly, monthly \\
\hline & Air temperature & ${ }^{\circ} \mathrm{C}$ & Daily, weekly, monthly \\
\hline & Atmospheric pressure & atmospheres & Daily, weekly, monthly \\
\hline & Relative humidity & percent & -- \\
\hline \multirow[t]{6}{*}{ Hydrographical } & Lake depth & meters & Daily, weekly, monthly \\
\hline & Lake surface area in relation to depth & $\mathrm{m}^{2}$ and meters & -- \\
\hline & Epilimnion temperature & ${ }^{\circ} \mathrm{C}$ & Daily, weekly, monthly \\
\hline & Epilimnion depth & meters & Daily, weekly, monthly \\
\hline & Inflow rate and inflow depth & $\mathrm{m}^{3}$ per day and meters & Daily, weekly, monthly \\
\hline & Outflow rate and outflow depth & $\mathrm{m}^{3}$ per day and meters & Daily, weekly, monthly \\
\hline \multirow[t]{3}{*}{ VOC mass inputs } & Atmospheric concentrations & ppbv & Daily, weekly, monthly \\
\hline & Initial lake concentration & $\mu g / L$ & -- \\
\hline & $\begin{array}{l}\text { Inputs to the lake other than the atmosphere } \\
\text { (motorboats and others sources) }\end{array}$ & $\begin{array}{l}\text { kilograms per unit time } \\
\text { (day, week, or month) }\end{array}$ & Daily, weekly, monthly \\
\hline \multirow{3}{*}{$\begin{array}{l}\text { Physical-chemical } \\
\text { properties }\end{array}$} & Degradation rates in the epilimnion and hypolimnion & per day & Daily, weekly, monthly \\
\hline & Henry's law constant (temperature dependent) & Pa-m $\mathrm{m}^{3} / \mathrm{mole}$ & -- \\
\hline & Molecular weight & grams per mole & -- \\
\hline
\end{tabular}


lations designed to test model characterizations of mixing between the epilimnion and hypolimnion, volume changes due to inflow and outflow, and air-water gas exchange. A hypothetical lake with a constant surface area of 2,000 square meters, a depth of 50 meters, water and air temperatures equal to 10 degrees Celsius, and relative humidity of 100 percent were used for the simulations. The VOC selected for these hypothetical lake simulations was MTBE. Input time series were given as monthly averages.

Seven lake mixing and dilution simulations were done. The mass balance of MTBE was simplified by setting the wind speed to 0 meters per second so that gas exchange was shut off. No anomalous results were found for any of the mixing and dilution test cases. These seven simulations demonstrated that the characterization of mixing and dilution were implemented correctly in the LakeVOC model.

Two simulations were used to test the model's characterization of air-water gas exchange. The first simulation tested the air-water gas flux of MTBE with a constant wind speed as a driving force for gas exchange. The mass balance of MTBE in the first simulation was simplified by setting the atmospheric concentration of MTBE to zero, assuming there were no inflows or outflows, and by using an unstratified lake. The second simulation tested whether the lake would come to equilibrium with respect to an atmospheric concentration of MTBE with constant wind speed. These two simulations showed that the characterization of the air-water gas exchange was correctly represented by the LakeVOC model.

\section{Simulations Using an Actual Reservoir}

Additional simulations were completed to verify results from the LakeVOC model for Lake Perris, located in Riverside County, California, which is a water-supply reservoir. Water-quality data provided by the Metropolitan Water District of Southern California (MWDSC) were used in the simulations. The model's accuracy in estimating: (1) the depth and volumes of the epilimnion and hypolimnion, and (2) the concentrations of a VOC with daily, weekly, and monthly hydrographic, meteorologic, and VOC input parameters was assessed using two simulations.

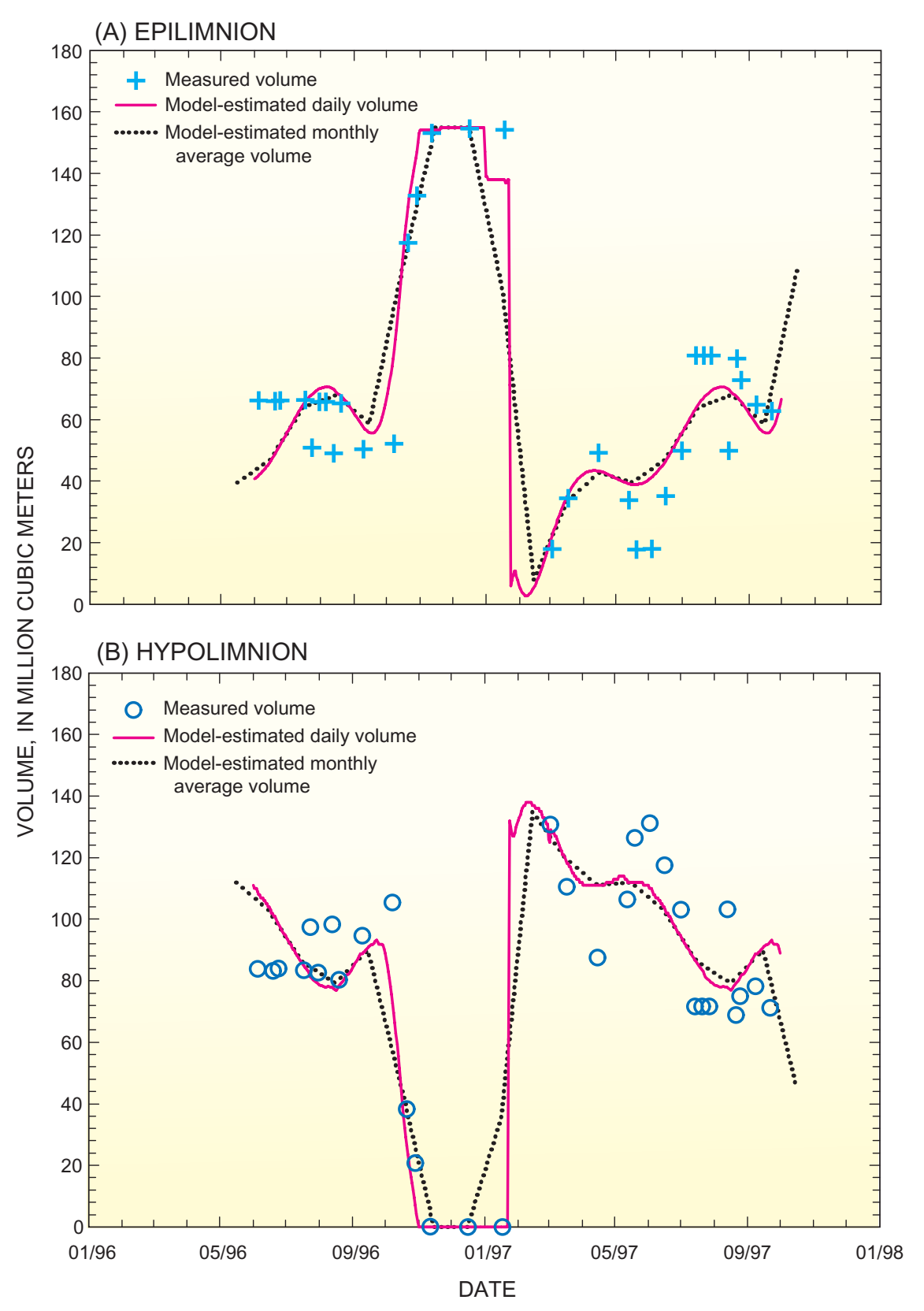

Figure 2. Comparison of measured and model-estimated daily and monthly-averaged lake volumes in (A) epilimnion and (B) hypolimnion, Lake Perris, California, June 1996 through September 1997.

In the first simulation, dissolved oxygen (DO) was used to calibrate Lake Perris' hydrodynamics using the LakeVOC model for June 1996 through December 1998. Model calibration of estimated-to-measured DO concentrations was completed by adjusting the values of the epilimnion depth within the thermocline and applying a first-order degradation rate for DO in the hypolimnion when the lake was stratified (May through September). The simulation reproduced the general features of seasonal variation of DO within the reservoir.

Once the model calibration was completed, a comparison was made of measured and estimated depths and volumes for both the epilimnion and hypolimnion. The difference between the measured epilimnion depths and the calibrated model epilimnion depths ranged from 0 to 3.15 meters. The differences in the epilimnion depths were within the range of the measured thermocline of the stratified reservoir. The lake volumes also compared 
well, with the model-estimated daily and monthly average lake volumes not changing as rapidly as the measured lake volumes but following the observed trend (fig. 2). The large drop in the epilimnion volume and large increase in the hypolimnion volume between November 1996 and January 1997 in figure 2 are associated with lake destratification (turnover).

In the second simulation, boating activity and estimated mass-emission rates from marine engines were used to estimate the concentrations of MTBE in the epilimnion and hypolimnion of Lake Perris using the LakeVOC model. California Park Service information (California Park Service, written commun., February 16, 1999) was used to estimate the number of boats using the main boat ramps at Lake Perris. A marine-engine mass-emission rate of 5.5 micrograms of MTBE per boat per hour was assumed and was based on the estimates made by Anderson (1997) specifically for Lake Perris. The California Park Service boat count estimates and the Anderson (1997) mass-emission rate were combined to estimate the temporal MTBE mass-load inputs for Lake Perris. Atmospheric MTBE concentrations were averaged from the four nearest California Air Resources Board sites.

The measured MTBE concentrations for Lake Perris on specific monitoring dates were averaged vertically over the calibrated epilimnion and hypolimnion depths and spatially across the reservoir to obtain an average concentration for each of the two layers within the reservoir. These measured-averaged concentrations were compared to the modelestimated MTBE concentrations using daily, weekly, and monthly time series for required model inputs. Only the results of the calibration and verification process for daily input time series are shown in this report.

The model was calibrated for June 1996 through December 1997 and produced median differences between the measured-averaged and model-estimated MTBE concentrations of 0.15 microgram per liter for the epilimnion (fig. 3A) and -1.1 micrograms per liter for the

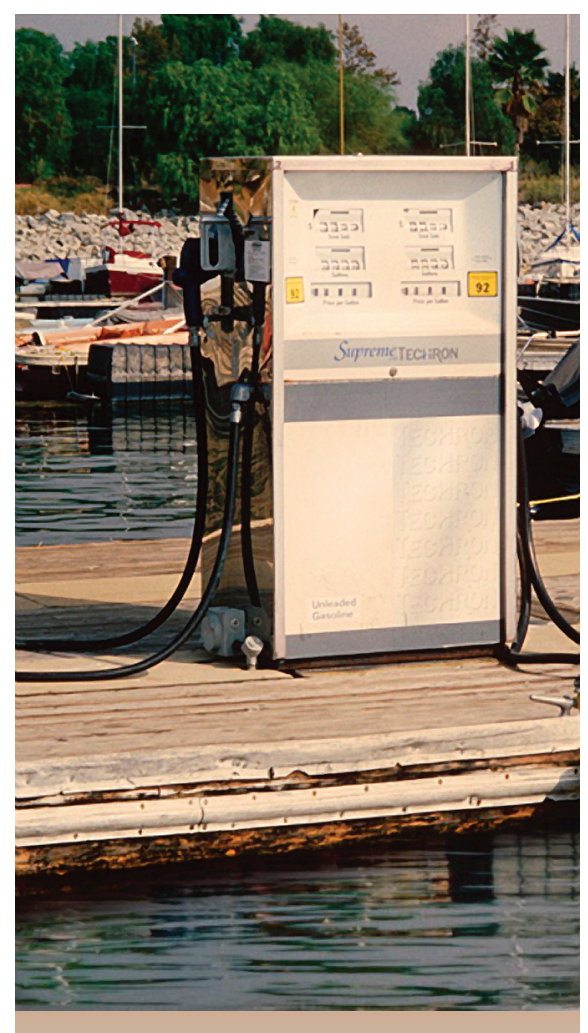

MTBE and other VOCs can be released into lakes and reservoirs directly from boat and personal watercraft engines, as well as from accidental spills at fueling stations (Photograph by John S. Zogorski, U.S. Geological Survey).
(A) EPILIMNION

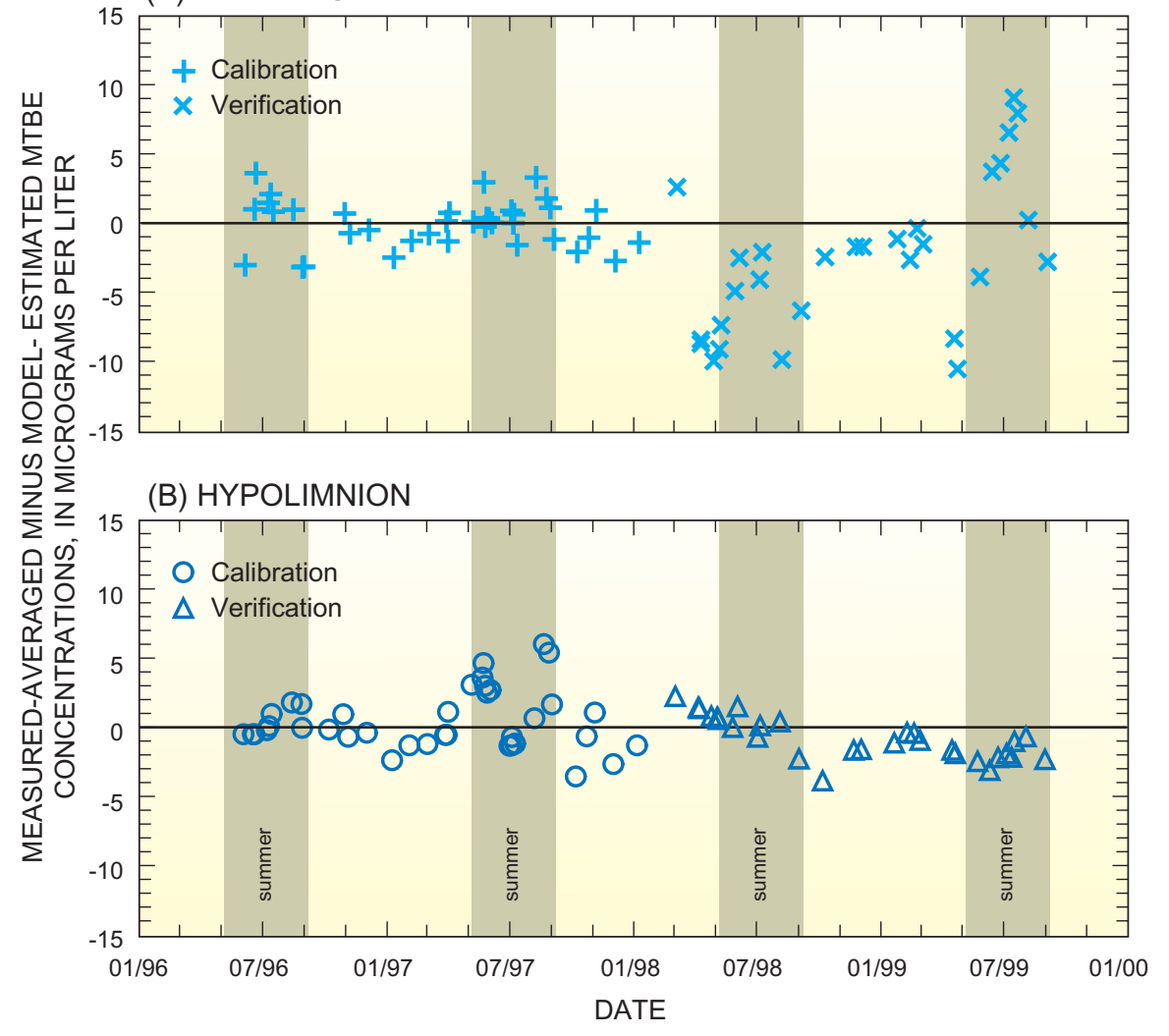

Figure 3. Differences in measured-averaged and model-estimated MTBE concentrations from daily model inputs in (A) epilimnion and (B) hypolimnion, Lake Perris, California, June 1996 through September 1999. hypolimnion (fig. 3B). Based on the median difference and the large range in the model-estimated concentrations in the epilimnion (fig. 4A), the model calibrated reasonably well for the epilimnion. In contrast, a narrow range in the modelestimated concentrations compared to a wider range in the measured-averaged concentrations is evident for the hypolimnion (fig. 4B). The poorer calibration in the hypolimnion could be caused by the model not characterizing episodic mixing events across the thermocline or mixing that does not change the mean epilimnion depths.

The model was verified for the period January 1998 to September 1999 and produced median concentration differences between the measured-averaged and model-estimated MTBE concentrations of -2.5 micrograms per liter for the epilimnion (fig. 3A) and -1.1 micrograms per liter for the hypolimnion (fig. 3B). As shown in figure 3 , a seasonal variation of the concentration differences occurs 
(A) EPILIMNION

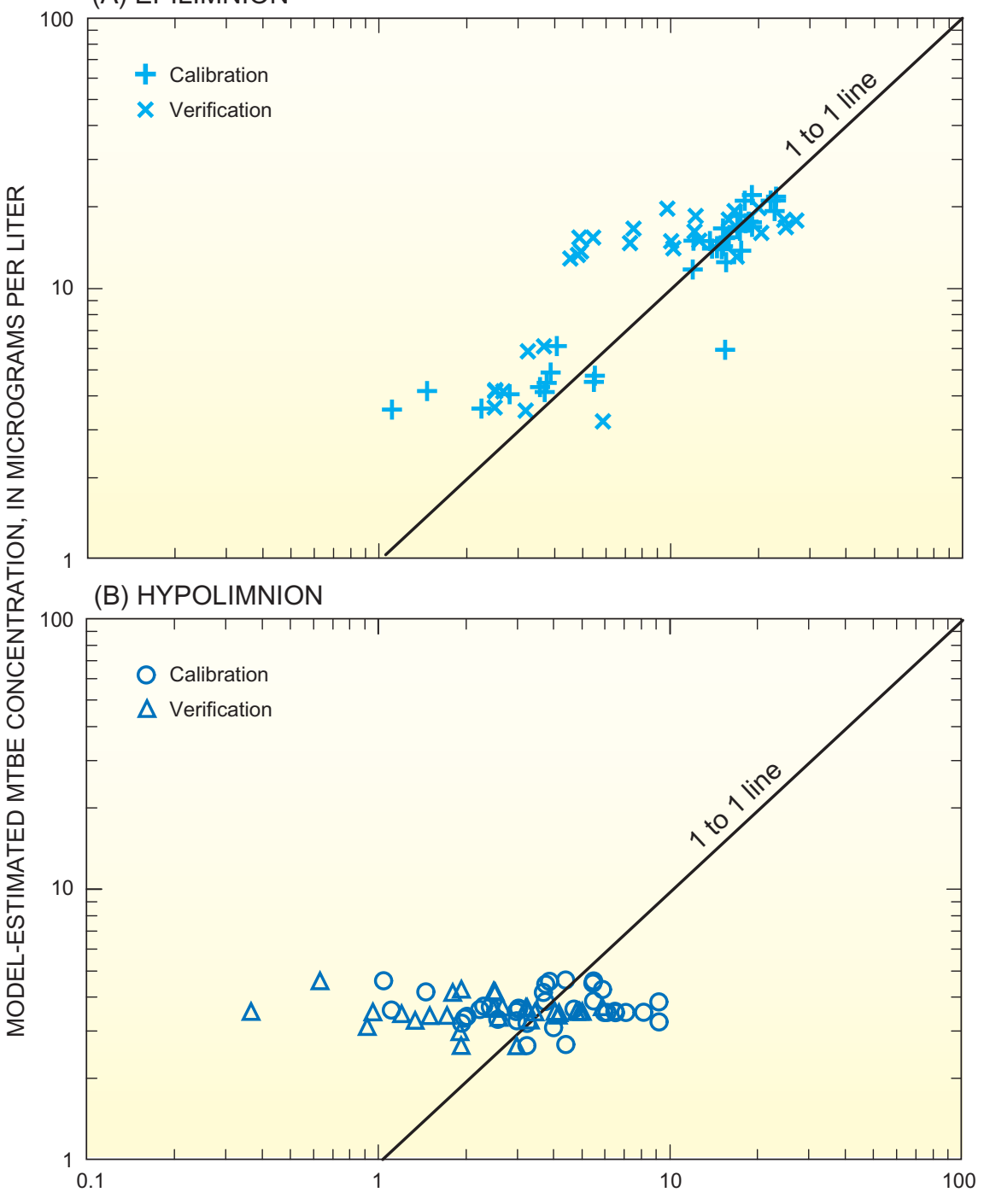

MEASURED-AVERAGED MTBE CONCENTRATION, IN MICROGRAMS PER LITER

Figure 4. Comparison of model-estimated and measured-averaged MTBE concentrations from daily model inputs in (A) epilimnion and (B) hypolimnion, Lake Perris, California, June 1996 through September 1999.

with larger concentration differences in both the epilimnion and hypolimnion occurring during the summer, or high recreational-use period when MTBE concentrations are highest. Part of the larger differences in the verification process likely was caused by the lack of complete boat use information for the verification period (compared to the calibration time period) and, possibly, to a partial fleet changeover to newer marine engine technology, with lesser emissions of gasoline-related compounds, during the verification time period.

Collectively, the simulations based on daily model input parameters showed that the LakeVOC model adequately estimated concentrations for the epilimnion with a larger range in the differences between the measured-averaged and model-estimated concentrations for the hypolimnion. As the time scale of the model inputs increased (daily to weekly to monthly), the median and range of differences between the measured-averaged concentrations and the model-estimated concentrations increased, especially for the hypolimnion (Bender and others, 2003). Because of the increasing differences as the time scale is increased, daily model inputs will produce more accurate model-estimated concentrations.

\section{Model Compatibility and Availability}

The LakeVOC computer code is written in Fortran and compiled using Compaq Visual Fortran V 6.6a ${ }^{1}$. LakeVOC has been tested under all 32-bit versions of Microsoft Windows operating systems through Windows XP (Home and Professional). Documentation of the LakeVOC model is available as a U.S. Geological Survey Open-File Report (Bender and others, 2003). This documentation, along with the executable version and example input parameter files, can be accessed on the Internet at the following web site address:

http://pubs.water.usgs.gov/ofr03-212/

\footnotetext{
${ }^{1}$ The use of firm, trade, and brand names in this report is for identification purposes only and does not constitute endorsement by the U.S. Government.
}

\section{References Cited}

Anderson, Michael, 1997, Predicted MTBE concentrations in the Eastside Reservoir: Soil and Environmental Science, April, p. 2-7.

Baehr, A.L., and Reilly, T.J., 2001, Water quality at lakeside communities in Sussex and Morris Counties, New Jersey, 1998-1999, with emphasis on methyl tert-butyl ether (MTBE) and other fuel related compounds: U.S. Geological Survey Water-Resources Investigation Report 01-4149, 86 p.

Baehr, A.L., and Zapecza, O.S., 1998, Methyl tert-butyl ether (MTBE) and other volatile organic compounds in lakes in Byram Township, Sussex County, New Jersey, summer 1998: U.S. Geological Survey Water-Resources Investigation Report 98-4264, 8 p.

Bender, D.A., Asher, W.E., and Zogorski, J.S., 2003, LakeVOC-A deterministic model to estimate volatile organic compound concentrations in lakes and reservoirs: U.S. Geological Survey Open-File Report 03-212, 283 p.

Boughton, C.J., and Lico, M.S., 1998, Volatile organic compounds in Lake Tahoe, Nevada and California, JulySeptember 1997: U.S. Geological Survey Fact Sheet 055-98, 2 p. 


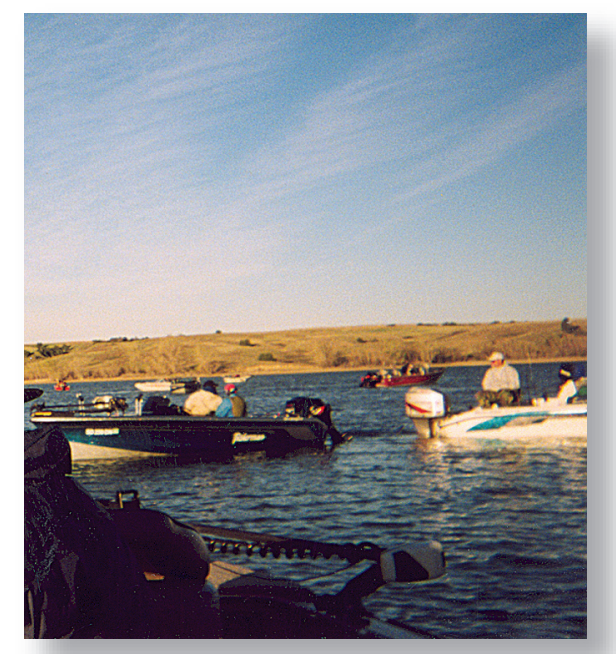

Angostura Reservoir, South Dakota (Photograph by Gregory C. Delzer, U.S. Geological Survey).

Dale, M.S., Koch, Bart, Losee, R.F., Crofts, E.W., and Davis, M.K., 2000, MTBE in southern California waterMotorized recreational watercraft were the predominant mode of contamination in reservoirs: Journal of the American Water Works Association, v. 92, no. 8, p. $42-51$.

Gabele, P.A., and Pyle, S.M., 2000, Emissions from two outboard engines operating on reformulated gasoline containing MTBE: Environmental Science and Technology, v. 34, no. 4, p. 368-372.
Jüttner, Friedrich, 1988, Motor-boatderived volatile organic compounds (VOC) in lakewater: Z. WasserAbwasser-Forsch., v. 21, p. 36-39.

Jüttner, Friedrich, 1994, Emission of aromatic hydrocarbons and aldehydes into the water by a four-stroke outboard motor-quantitative measurements: Chemosphere, v. 29, no. 2, p. 191-200.

Jüttner, Friedrich, Backhaus, Diedrich, Matthias, Uwe, Essers, Ulf, Greiner, Rolf, and Mahr, Bernd, 1995a, Emissions of two- and four-stroke outboard engines-I. Quantification of gases and VOC: Water Research, v. 29, no. 8, p. 1976-1982.

Jüttner, Friedrich, Backhaus, Diedrich, Matthias, Uwe, Essers, Ulf, Greiner, Rolf, and Mahr, Bernd, 1995b, Emissions of two- and four-stroke outboard engines-II. Impact on water quality: Water Research, v. 29, no. 8, p. 19831987.

Lewis, W.K., and Whitman, W.G., 1924, Principles of gas adsorption: Industrial and Engineering Chemistry, v. 16, no. 12, p. 1215-1220.

Lico, M.S., and Pennington, Nyle, 1999, Concentrations and distribution of manmade organic compounds in the Lake Tahoe Basin, Nevada and California, 1997-99: U.S. Geological Survey Water-Resources Investigations Report 99-4218, 12 p.
Mahler, B.J., 2000, Determining the occurrence of pesticides and volatile organic compounds in public watersupply source waters in Texas: U.S. Geological Survey Fact Sheet 010-00, 2 p.

Rathbun, R.E., 2000, Transport, behavior, and fate of volatile organic compounds in streams: Critical Reviews in Environmental Science and Technology, v. 3, no. 2, p. 129-295.

Reuter, J.E., Allen, B.C., Richards, R.C., Pankow, J.F., Goldman, C.R., Scholl, R.L., and Seyfried, J.S., 1998, Concentrations, sources, and fate of the gasoline oxygenate methyl tert-butyl ether (MTBE) in a multiple-use lake: Environmental Science and Technology, v. 32, no. 23, p. 3666-3672.

Schwarzenbach, R.P., Gschwend, P.M., and Imboden, D.M., 1993, Environmental organic chemistry: New York, Wiley-Interscience, $681 \mathrm{p}$.

van Donkelaar, P., 1988, Comments on an article by Friedrich Jüttner "Motor-boat-derived volatile organic compounds (VOC) in lakewater": Z. Wasser-Abwasser-Forsch., v. 21, p. 255-256.

Wanninkhof, R., Ledwell, J., and Crusius, J., 1991, Gas transfer velocities on lakes measured with sulfur hexafluoride, in Wilhelms, S.C., and Gulliver, J.S., eds., Air-water mass transfer: New York, American Society of Civil Engineering, p. 441-458.

Information on MTBE and other volatile organic compounds sampled by the U.S. Geological Survey's National Water-Quality Assessment Program can by found at: http://water.usgs.gov/nawqa/vocs

For more information about the LakeVOC model, detailed report, and supporting files contact:

David A. Bender

U.S. Geological Survey 1608 Mt. View Road Rapid City, SD 57702 (605) 355-4560 ext. 248 dabender@usgs.gov 